\title{
A DIVERSIDADE PAISAGÍSTICA dOS “CAMPOS” NAS ICONOGRAFIAS DE FloRENCE E dE MARTIUS: ALGUNS ASPECTOS DO CERRADO DA PRIMEIRA METADE DO SÉCULO XIX
}

THE LANDSCAPE DIVERSITY OF “CAMPOS" IN FLORENCE AND MARTIUS'S ICONOGRAPHIES: SOME ASPECTS OF CERRADO OF THE FIRST HALF OF THE 19TH CENTURY

Ana Marcela França de Oliveira* anamarcelaayos@gmail.com

RESUMO: Tendo como foco principal os registros visuais feitos pelo botânico alemão Carl F. von Martius (1794-1868) e pelo artista francês Hercule Florence (1804-1879) buscarei mostrar como apontaram para a diversidade paisagística das extensões florísticas que abrangem atualmente parte do Cerrado. A flora típica de parte da província de Minas Gerais e do centro-oeste do Brasil tem as suas características apontadas por esses viajantes, sendo as suas peculiaridades apreendidas entre a estranheza, a poesia e a admiração. Sensações distintas se despertavam à medida que eles atravessavam paisagens diversificadas, como é característico das regiões que compreendem atualmente o bioma em questão. Desde o "horror" ao encantamento, tentarei expor no presente artigo como os "cerrados" foram registrados e valorizados por eles e como tais imagens podem servir de testemunhos de usos pretéritos do ambiente em questão.

PALAVRAS-CHAVE: História Ambiental, Viajantes, Paisagem.

ABSTRACT: With the central focus on the visual records made by the German botanist Carl F. von Martius (1794-1868) and the French artist Hercule Florence (1804-1879) I will try to show how they pointed to the landscape diversity of the floristic extensions that currently cover part of the Cerrado. The typical flora from part of the province of Minas Gerais and the center-west of Brazil had its characteristics pointed out by these travelers and its peculiarities were apprehended by its strangeness, poetry and admiration. Distinct sensations awakened when they crossed different landscapes, like it is characteristic of the regions that currently cover the biome in question. From the horror to the enchantment, I will try to explain in this article how the cerrados were registered and valued by them and how such images can serve as testimonies of past uses of the mentioned environment.

KEYWORDS: Environmental History, Travelers, Landscape.

Porta de entrada para o Brasil, após a vinda da família real portuguesa em 1808, a cidade do Rio de Janeiro recebeu uma quantidade expressiva de naturalistas e outros profissionais que vinham da Europa com objetivo de coletar exemplares e informações da fauna, da flora, dos costumes, entre outras coisas, das diferentes regiões do Brasil. Partindo então do Rio de Janeiro, de um ambiente favorecido pela umidade e exuberância da Mata Atlântica, os viajantes rumavam para o interior brasileiro com o objetivo de coletar materiais e informações sobre uma extensão praticamente desconhecida e muitas vezes inóspita. Inédita para muitos deles, a natureza dos trópicos tornava-se surpreendente por sua estranheza, o que causava uma infinidade de sensações naqueles que a experimentavam. A diferença de clima e de vegetação entre as matas úmidas do litoral e as das extensões mais áridas do interior

\footnotetext{
* Doutora pelo Instituto de História- Universidade Federal do Rio de Janeiro, na área de História Social, com ênfase em História Ambiental e em História da Arte. Doutorado sanduíche, subsidiado pela Capes, na Birkbeck, University of London, na Inglaterra.
} 
apresentava aos estrangeiros a diversidade das paisagens brasileiras, marcadas muitas vezes por sua singular composição. E essa diferença se faz visível nas imagens por eles realizadas ou descritas nos relatos.

Tendo como foco principal os registros visuais feitos pelo naturalista alemão Carl F. von Martius (1794-1868) e pelo artista francês Hercule Florence (1804-1879) buscarei mostrar como foi observada a diversidade paisagística das extensões florísticas que abrangem atualmente parte do bioma Cerrado ${ }^{1}$. Ao mesmo tempo será visto que em suas imagens e relatos se faz possível perceber alguns aspectos que indicariam a transformação ou não da paisagem durante esses cerca de duzentos anos de diferença da passagem deles para a atualidade.

A escolha dos referidos viajantes deve-se ao fato de que durante o desenvolvimento da minha tese percebi nas palavras de Florence e de Martius uma observação especial às particularidades do cerrado, em que a beleza e o valor dessas vegetações foram salientados por eles. É necessário deixar claro que a visão de ambos sobre a natureza brasileira em geral é bastante ambígua, em que junto a um sentimento de repulsa, por exemplo, pode-se ter uma visão encantadora sobre uma espécie de flor nativa. Sendo as imagens atreladas aos relatos no contexto das viagens, considero de extrema riqueza o primeiro tomo da obra Flora Brasiliensis, de Martius. Aí as gravuras têm igual importância às palavras, não sendo à estas submetidas, trazendo assim informações visuais ainda hoje valiosas não só para os profissionais da área das ciências naturais, mas também para os historiadores ambientais, da arte, da história das ciências, entre outras. Deste modo, para o presente artigo tal obra de Martius será central devido à proposta de se ter o conhecimento da vasta natureza brasileira a partir de suas "Tábuas fisionômicas" (Tabulae Physiognomicae). O diário de Florence também traz interessantes imagens sobre o cerrado e a narrativa que as acompanha apresenta uma visão em geral bastante pitoresca sobre parte do centro-oeste brasileiro; o que me parece surpreendente quando se trata desta região, pois foi por muito tempo, se ainda não o é, estigmatizada como um sertão longínquo constituído por uma vegetação pobre e feia. Creio, portanto, que as impressões e imagens

\footnotetext{
${ }^{1}$ Será utilizado no artigo o conceito de Cerrado elaborado por Ribeiro e Walter (2008), por sua ampla difusão e uso pelos órgãos oficiais relacionados ao meio ambiente, uma vez que será discutido que os viajantes ajudaram a esboçar o que se compreende atualmente como o território nacional desde as suas características vegetativas.
} 
realizadas por esses viajantes não somente trazem observações sobre o cerrado oitocentista, mas oferecem informações pessoais sobre a vivência nos "cerrados", o que traz para a atualidade testemunhos de experiências de uma natureza de cerca de duzentos anos atrás. São paisagens que podem auxiliar o historiador a compreender melhor as interações pretéritas entre os humanos e a natureza de uma certa localidade. Até porque, se vê em seus relatos que sensações distintas se despertavam à medida que eles atravessavam paisagens diversificadas, como é característico das regiões que compreendem atualmente o bioma em questão. É preciso ter em conta que tais imagens eram muitas vezes esboçadas durante a viagem e finalizadas quando de regresso as suas terras natais, em que em sua maioria eram reelaboradas e adequadas às necessidades do autor. E o que interessa ao presente artigo é justamente o fato de que essas imagens trazem assim tanto informações sobre os aspectos fitofisionômicos do Cerrado quanto também informações sobre como era compreendido e apreendido o universo natural. Assim, desde o "horror" ao encantamento, tentarei expor no presente artigo como que os "cerrados" foram registrados, vivenciados e valorizados por eles.

Deve-se notar, antes de qualquer coisa, que eles não tinham a mesma concepção que se tem atualmente sobre biomas ou domínios e que, por diversas vezes, tanto Martius quanto Florence nomeavam as matas que compreendiam a região que o agrega simplesmente como campos ou cerrados. Não se percebe ser feito por eles o uso de nenhuma designação precisa ou formal sobre os conjuntos de vegetação, salvo às denominações já usadas pelos habitantes locais. Nesse sentido, a mirada de ambos viajantes estava, sobretudo, direcionada aos aspectos sobre a vegetação, solo, clima, a topografia e os rios das distintas regiões atravessadas, resultando em "quadros da natureza". Essa mirada gerou uma visão mais abrangente das diferentes extensões vegetativas, resultando no registro de paisagens que informavam as suas características fitofisionômicas, com detalhes de espécies da flora. Diante disso, se faz mais coerente usar, em relação aos viajantes, o termo paisagem para designar as extensões vegetativas descritas por eles, pois biomas e domínios, além de anacrônico, já pertencem a uma complexidade histórica e discussão conceitual que foge à originalidade de seus olhares pioneiros. Assim, quando for usado o 
termo bioma neste artigo será a título de compreensão e comparação da extensão atual² com a da primeira metade do século XIX a qual eles se referiam.

Também à diferença da atualidade, Martius e Florence perceberam nessas extensões uma diversidade paisagística que não se limitou ao seu aspecto cerrado, ou seja, fechado - palavra esta, de origem espanhola, que acabou por dar nome ao bioma, e que procura traduzir a característica savânica. O apuro da observação de ambos viajantes se expandiu para a larga e variável extensão dos "campos", resultando na descrição das diversas paisagens que compunham uma extensão que a primeiro momento devia soar como homogênea, a respeito de sua formação vegetativa. Ao contrário, eles se abriram à variedade de sua beleza e formação.

Desta maneira, a flora típica de parte da província de Minas Gerais e do centrooeste do Brasil tiveram as suas características apontadas por esses viajantes, sendo as suas peculiaridades apreendidas entre a estranheza, a poesia e a admiração. E nesse percurso tais personagens, cada qual a sua maneira, ajudaram a delinear o território brasileiro por meio da diversidade de suas paisagens.

\section{O Cerrado}

O bioma Cerrado hoje se distribui principalmente, pelo Planalto Central Brasileiro, nos Estados de Goiás, Tocantins, Mato Grosso, Mato Grosso do Sul, parte de Minas Gerais, Bahia e Distrito Federal, no qual engloba $100 \%$ de seu território ${ }^{3}$. Há outras áreas de cerrado, chamadas periféricas ou ecótonos (áreas de transição ambiental), que são transições com os biomas Amazônia, Mata Atlântica e Caatinga. ${ }^{4}$ A vegetação que comumente qualifica o bioma Cerrado apresenta algumas características gerais como gramíneas e plantas baixas, esparsas e de aparência seca. Com duas estações bem definidas, uma de seca e outra de chuva, as árvores em sua maioria são relativamente baixas, podendo alcançar até vinte metros de altura e são disseminadas em meio a arbustos. Características típicas da vegetação em algumas regiões também são troncos retorcidos ou tortuosos, de baixo porte, com folhas grossas e cascas espessas. Algumas árvores tem as suas raízes profundas e podem atingir o lençol freático localizado de quinze a vinte metros do solo. Já as gramíneas têm raízes mais

\footnotetext{
${ }^{2}$ http://www.agencia.cnptia.embrapa.br/Agencia16/AG01/Abertura.html

${ }^{3}$ Fonte: http://www.brasil.gov.br/sobre/meio-ambiente/geografia;

http://www.agencia.cnptia.embrapa.br/Agencia16/AG01/Abertura.html

${ }^{4}$ Fonte: http://www.ibama.gov.br/ecossistemas/cerrado.htm
} 
superficiais, como um "tapete rasteiro", ficando com a aparência bastante seca nos períodos de pouca chuva, o que pode ocasionar incêndios frequentes. Porém, o que pode parecer pobre à primeira vista, em termos de flora e fauna, concentra uma grande biodiversidade, sendo o Cerrado uma das savanas ${ }^{5}$ mais ricas em variedades de ecossistemas ${ }^{6}$. Indo de formações campestres a formações florestais, as paisagens se diversificam entre um campo árido, passando por terrenos de arbustos baixos, à áreas de cobertura mais robusta, como o Cerradão ${ }^{7}$. Diante disso, a diversidade de paisagens é uma forte característica desse extenso bioma que compõem grande parte do território brasileiro. Pensar nele como dotado unicamente de uma vegetação seca e de um solo desnutrido, como ficou estigmatizado, é ignorar a riqueza de sua biodiversidade e a peculiaridade de sua regeneração.

A diversidade de paisagens inclui desde ambientes florestais, nos quais a vegetação é mais densa, como o Cerradão, onde o número de árvores por hectare é onze vezes maior do que as áreas abertas, como o campo sujo, e cerca de duas vezes e meia em relação a áreas intermediárias, como o Cerrado (WWF, 1995). (...) Foram as formações savânicas que acabaram por melhor caracterizar esse bioma e dar origem ao nome que passou a identificá-lo, dado pelos primeiros colonizadores e estudiosos da região. Por se encontrar em uma situação intermediária entre as "matas" e os "campos"; por serem mais fechadas que estes, acabaram sendo identificadas como um "campo cerrado" ou simplesmente "Cerrado". (RIBEIRO, 2002, p. 252)

A fauna, do mesmo modo, apresenta uma variedade de animais e insetos, endêmicos ou não, como o tamanduá-bandeira, o lobo-guará ou o tatu-canastra. Também se encontram as nascentes que contribuem para importantes bacias, tais como Amazônia/Tocantins, São Francisco e Prata $^{8}$. Sua constituição hidrológica é, desta forma, bastante rica, composta por uma rede hídrica extensa e extremamente importante para alimentar muitos rios do país.

Anteriormente à ocupação colonial predominava na região do centro-oeste brasileiro os indígenas pertencentes ao tronco linguístico Macro-Jê, os chamados Tapuias pelos seus inimigos Tupis-guaranis (BERTRAN, 2011; RIBEIRO, 2002). Segundo José Augusto

\footnotetext{
${ }^{5}$ Segundo Della Giustina o termo savana e cerrado tem diversas definições, que variam em aspectos como clima, fitogeografia, florística, geomorfologia, influência do fogo, etc..., sendo que a primeira classificação de savanas como unidade fitogeográfica foi atribuída a Martius. Ver mais em: Della Giustina, Carlos Christian. Degradação e Conservação do Cerrado: uma história ambiental do estado de Goiás. Brasília. Tese de Doutorado. Centro de Desenvolvimento Sustentável. Universidade de Brasília, 2013.

${ }^{6}$ Fonte: http://www.ibama.gov.br/ecossistemas/cerrado.htm

${ }^{7}$ Segundo a Embrapa: "São descritos onze tipos principais de vegetação para o bioma Cerrado, enquadrados em formações florestais (Mata Ciliar, Mata de Galeria, Mata Seca e Cerradão), savânicas (Cerrado sentido restrito, Parque de Cerrado, Palmeiral e Vereda) e campestres (Campo Sujo, Campo Limpo e Campo Rupestre). Considerando também os subtipos neste sistema são reconhecidas 25 tipos de vegetação."

http://www.agencia.cnptia.embrapa.br/Agencia16/AG01/arvore/AG01_23_911200585232.html

${ }^{8}$ Fonte: http://www.mma.gov.br/biomas/cerrado
} 
Pádua, a região do Cerrado começou de fato a ser ocupada pela colônia no início do século XVIII, com a expansão mineira "que avançou pela fronteira entre a Mata Atlântica e o Cerrado para além da Serra do Espinhaço" (PÁDUA, 2009, p.137). Depois do advento da mineração e de sua decadência a pecuária predominou em algumas regiões, como foi o caso de Goiás, onde “A ocupação de Goiás esteve ligada, no início de sua colonização, à atividade mineradora do século XVIII. Passado o surto da exploração das lavras de ouro, a atividade pastoril tornou-se dominante" (DUTRA E SILVA, 2016, p. 265). A criação de gado é hoje bastante expressiva no centro-oeste do Brasil, tendo assim uma presença relevante de três séculos e que tende a cada dia mais se expandir. Já Martius fez comentários sobre a pecuária nos campos da província mineira, dizendo:

Visto que, em geral, somente a regiões florestais são propícias à agricultura, pode-se supor que a região do país coberta pelos campos, é preferencialmente habitada por aquela parte da população que vive da criação de gado ou da lavra de ouro (MARTIUS, 1943, p. 255).

Apesar do gado constituir boa parte da renda nessas áreas, elas sofriam na época uma "eminente decadência" ainda resultante da exploração aurífera ocorrida no século anterior (FUNES, 2013). Algo frequentemente relatado por Florence, como será citado adiante.

Diante dessa breve apresentação do Cerrado, serão analisadas as imagens de Florence e as atribuídas a Martius referentes, em especial, às formações savânicas e campestres (classificação EMBRAPA), pois tais vegetações pareceram aos olhos deles como curiosamente particulares. Desconhecidas esse tipo de formações para ambos, me pareceu fundamental expor esse material no âmbito da história ambiental.

\section{Rumo aos cerrados}

No mapa fitofisionômico que compõe as primeiras páginas de Flora Brasiliensis Martius mapeou as diferentes regiões do Império do Brasil a partir das características da flora de cada domínio, de maneira surpreendentemente semelhante à classificação oficial e atual do território brasileiro em seis biomas ${ }^{9}$. Baseando-se nos caminhos percorridos por ele próprio e por outros naturalistas e nas consequentes classificações de espécies nativas da

\footnotetext{
${ }^{9}$ Segundo o MMA: “O Brasil é formado por seis biomas de características distintas: Amazônia, Caatinga, Cerrado, Mata Atlântica, Pampa e Pantanal." (http://www.mma.gov.br/biomas)
} 
flora, Martius dividiu o Brasil em cinco áreas de acordo com a vegetação de cada uma delas. Dando nomes de deusas gregas a esses cinco domínios, eles poderiam ser compreendidos da seguinte forma: Dryades (flora da costa atlântica), Nayades (flora amazônica), Hamadryades (flora nordestina), Oreades (flora do Centro-Oeste) e Napeias (flora subtropical) ${ }^{10}$. Parte do Cerrado seria equivalente a região nomeada de Oreades, que na Mitologia Grega são as ninfas das montanhas, das grutas e das cavernas, e compreenderia partes das províncias de São Paulo, Minas Gerais, Goiás e Mato Grosso.

Diferentemente da classificação atual do território em biomas, Martius faz referência às formações vegetais que comporiam as diferentes regiões, enquanto que o termo bioma, criado no século XX, associa a fauna à flora, variando o conceito de acordo com os diferentes autores (COUTINHO, 2006). As descrições de Martius, como também de Florence, não deixam de considerar os animais nativos, ao contrário, eles os citam e os relacionam com o ambiente em que vivem, porém, não era esse o foco central de ambos; este era um tema que caberia ao zoólogo. Mesmo assim, flora e fauna aparecem com frequência em uma mesma imagem, uma vez que Martius e Florence tem influência do naturalista alemão Alexander von Humboldt, mais especificamente de seus "quadros da natureza". Em sua obra "Quadros da Natureza" (Ansichten der Nature Tableaux de la Nature), publicada em 1808, na Alemanha e França, o naturalista descreve as "cenas da natureza" através das composições artísticas e da escrita científico-literária para que o universo natural seja devidamente conhecido, de acordo com as suas ideias. Sua intenção era que pela união entre ciência e estética a totalidade da natureza fosse apreciada em uma "apresentação viva" (RICOTTA, 2000). Através desses quadros, as paisagens eram construídas pensando a sociabilidade dos indivíduos vegetais e a interatividade dos elementos que compõem um ambiente. Deste modo, segundo Coutinho, foi Humboldt quem empregou a palavra fitofisionomia pela primeira vez para descrever a vegetação (COUTINHO, 2006, p. 14) e Martius será fortemente influenciado por seu método descritivo.

Em relação à compreensão sobre a percepção de Martius sobre as matas do cerrado, uma dificuldade encontrada é o fato dele - assim como outros viajantes - chamar de campos

\footnotetext{
${ }^{10}$ Manual Técnico da Vegetação Brasileira, IBGE, 2012. Disponível em: http://biblioteca.ibge.gov.br/visualizacao/livros/liv63011.pdf
} 
a maior parte do país coberta de gramíneas, termo que utiliza a partir da denominação já usada pelos brasileiros da época, segundo ele: "Nós designamos 'campo', no sentido do brasileiro, todas as regiões cobertas de vegetação, que não formam propriamente florestas, e de um modo geral cremos poder admitir que dois terços de toda a área do Brasil apresentam campos, ao passo que o último terço está coberto pela floresta" (MARTIUS, 1943, p. 253). Estes campos teriam fisionomias variáveis conforme a localidade que se estivesse, tendo uma feição no sul que se diferenciaria da do norte. Ao se tratar do cerrado mineiro, o naturalista se aproxima da atual classificação das formações campestres:

O caráter fisionômico geral dos campos de Minas Gerais aparece modificado heterogêneamente em diferentes regiões. A diferença mais importante é aquela que é designada pelos brasileiros com os nomes de campo limpo e campo fechado, cerrado (35). Pois nem sempre apenas um manto de grama alta ou de plantas herbáceas cobre a planície dos campos (36), pois aqui e acolá distinguem-se moitas de arbustos ou de árvores baixas, as quais se apresentando, ora entrelaçadas em matagal cerrado, ora em grupos isolados, limitam a vista através da região. (MARTIUS, 1943, p. 256)

Neste trecho do discurso A fisionomia do reino vegetal no Brasil, de 1824, ele aponta para a diversidade paisagística desses campos, aproveitando designações já feitas pelos brasileiros. Também comenta sobre as peculiaridades dos arbustos, componentes de casca grossa e galhos tortuosos, em que as folhas têm o aspecto verde-acinzentado, no período de seca. O olhar de Martius demonstra aí a complexidade do cerrado: “Delicadeza, fina concepção e variedade bizarra, eis o caráter geral das formas vegetais domiciliadas nessa região" (MARTIUS, 1943, p.258). Já no seguinte trecho que compõe o discurso de 1824 o naturalista faz comentários mais pitorescos sobre a vegetação ao dizer que:

Muitas vezes a mão da natureza coordenou tão artisticamente essas formações de Malpighias com folhas douradas, de Banisterias multicores, de Erythroxylas rígidas, de ridentes Apocináceas e Paulínias trepadeiras, de graciosas Declieuxias e Cássias ridentes, que a gente pensa estar passeando por um parque. (MARTIUS, 1943, 256)

Isso pode ter ocorrido por ser próprio da época, como já dito, uma imagem ambígua sobre a natureza brasileira, que oscilava entre um olhar romântico e uma visão mais iluminista, sem que essas duas facetas se deslocassem necessariamente uma da outra. Mas creio também, e aí partindo do pressuposto da História Ambiental em levar em conta a influência do meio sobre aquele que o experimenta, que a variedade das paisagens própria do Cerrado possa ter despertado em Martius diferentes impressões. 
A litogravura que segue (Fig.1) foi desenhada por Martius em "13 do mês de junho" (MARTIUS, 1996) e apresenta, junto ao relato em Flora Brasiliensis, o aspecto da vegetação de parte de Minas Gerais, mais especificamente na região chamada de "Termos de Minas Novas" (hoje conhecida como Minas Novas).

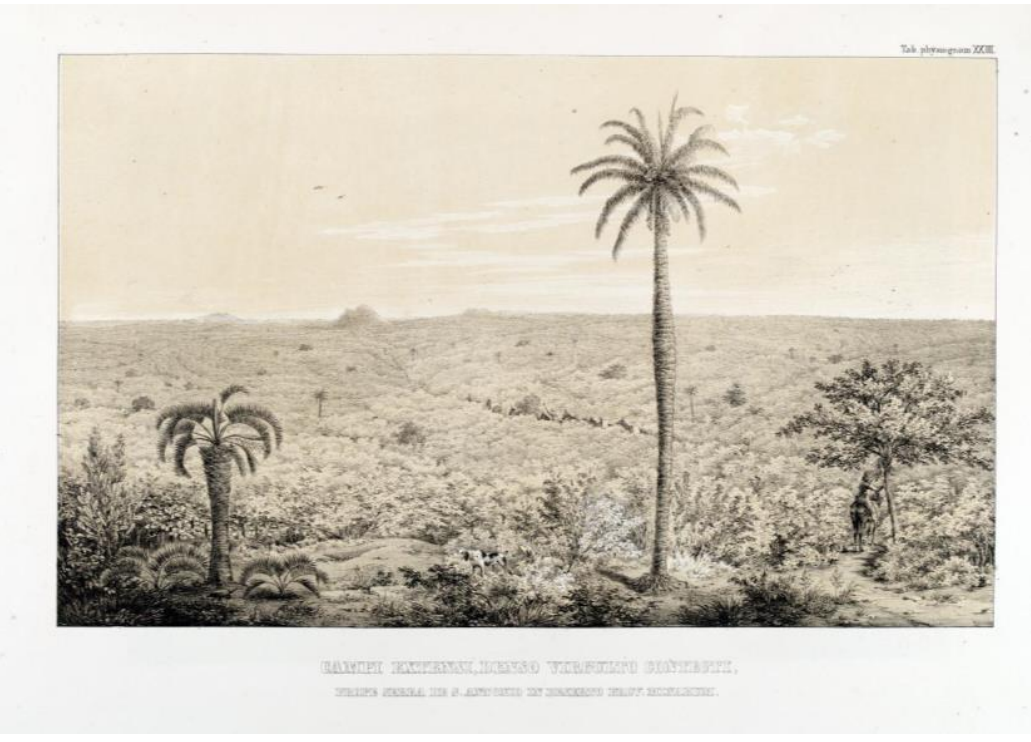

1.Prancha XXIII. Campos extensos, cobertos de denso matagal, perto da Serra de S. Antônio do Deserto, província de Minas. Cerrado representado por Martius, em Flora Brasiliensis. Fonte: Flora Brasiliensis (1996)

Nela predominam arbustos baixos e emaranhados por todo o segundo plano da imagem, em que algumas espécies de palmeiras e de árvores baixas estão espaçadas ao longo dessa vegetação fechada. Ao que parece estaria sendo aí representada o que se chama atualmente de fitofisionomia Campos, pois a descrição feita pelo naturalista e a prancha que a acompanha se assemelham bem com a qualificação atual. Na imagem tem-se uma ideia da altura dos arbustos predominantes ao avistar na diagonal que corta este mesmo plano a passagem de uma comitiva de viajantes por um caminho feito entre os arbustos. A partir da escala humana exposta através dos viajantes montados em seus cavalos pode-se imaginar a densidade das vegetações e o seu tamanho. Também se vê que essa região compreenderia um terreno basicamente plano e bastante descampado, com raras elevações ao fundo, em que no texto que acompanha a prancha o naturalista dá a entender que a caminhada foi cansativa devido ao calor que fazia. Assim Martius comenta sobre essa região:

Apenas pequenos vales cortam a sua extensão, e quando o olhar estrangeiro percorre tudo o que está coberto de densíssimas ramagens, é atingido por esta espécie de modo admirável. Cingido, pois, por esse imenso mar de frondes, e, como que oprimido pelo calor, não pode vencer com o corpo e observar esta imensa planície, senão montado a cavalo ou quando subir em alguma árvore alta, coisa rara ali. Seu arbusto é da espécie que os mineiros 
costumam chamar de cerrado ou carrasco: uma grande variedade de arbustos de fronde pouco sucosa, que, bem apertados entre si e frequentemente estão ligados por ramos circundantes de rebentos volúveis e de grinaldas de flores e não são interrompidos a não ser raramente por uma árvore mais alta, muito frondosa ou por uma palmeira. (MARTIUS, 1996, p.88) $)^{11}$

Acrescentando ainda que o viajante pode ser "levado a erro nesta imensidão de arbustos" (idem). Repara-se que o seu relato sobre essa "vegetação densíssima" se aproxima bem das informações que se tem atualmente sobre trechos arbustivos do Cerrado e a estampa esboçada por ele mesmo também se aproxima bastante do aspecto de alguns campos que compõem ainda hoje o bioma. Aí teríamos um testemunho de um tipo de paisagem que é ainda existente em partes do Cerrado. Para efeitos de restauração paisagística tal testemunho, junto a outras fontes e estudos mais detalhados, pode servir como um grande aliado se se busca um resgate ambiental. Sobre o clima Martius diz que "raramente as águas refrescam a vegetação desta região (...)" (MARTIUS, 1996, p. 89), em que predominaria um clima seco e quente nos meses correspondentes ao verão europeu (no Brasil compreenderia, então, os meses de inverno), o que provocaria a queda das folhagens e ramificações de características mais espessas. No primeiro plano da imagem há diversas espécies de arbustos e plantas com desenhos mais definidos, justamente para que com essa nitidez os leitores de sua obra pudessem reconhecer a flora regional. Animais estão aí registrados, como é o caso dos cachorros, que parecem estar acompanhando a comitiva, e dois tatus que se encontram na parte esquerda da composição. Ao fim da descrição dessa prancha, Martius cita algumas espécies da flora que habitam esses campos, sendo que umas ilustram a estampa:

Das plantas que crescem nesta região, convém enumerar apenas uma parte. Notam-se várias bignoneáceas dos gêneros Anemopaegma, Jacaranda $e$ Phitecoctenium, Acacia, Mimosa e várias Cassia, Qualea, Callisthena, Kielmeyera, Ochna, vários gêneros de malpighiáceas, Myrcina, Lucuma, Aspidosperma, Saparattantehelium, Annona, Delimae, Croton, Lychnophora, (...) e da ordem das palmeiras Cocos flexuosa, capitata, Diplothemium campestre, Astrocaryum campestre, Acrocomia sclerocarpa. (MARTIUS, 1996, p. 89)

Outra imagem que compõe Flora Brasiliensis e que retrata o cerrado é a prancha III (Fig.2). No texto que acompanha a ilustração Martius expressa primeiramente a variedade de

\footnotetext{
${ }^{11} \mathrm{Em}$ A fisionomia do reino vegetal Martius faz referência a esse tipo de vegetação em Minas, onde os brasileiros a chamavam, segundo ele, de "campo acarrascado", a diferenciando do "campo acatingado". (Martius, 1943)
} 
paisagens que formam a província de Minas Gerais, onde "Não há estilo com que possa um europeu descrever, nem cores com que possa pintar, a diáfana serenidade destes céus ou a audácia destes montes" (MARTIUS, 1996, p.28). A atual cidade de Minas Novas, segundo o IBGE, compreende os biomas Cerrado e Mata Atlântica ${ }^{12}$ e como indicado no texto que acompanha a prancha a paisagem retratada seria semelhante as do Oeste, em direção à província de Goiás e as do Norte, em direção à Bahia, sugerindo o atual Cerrado.

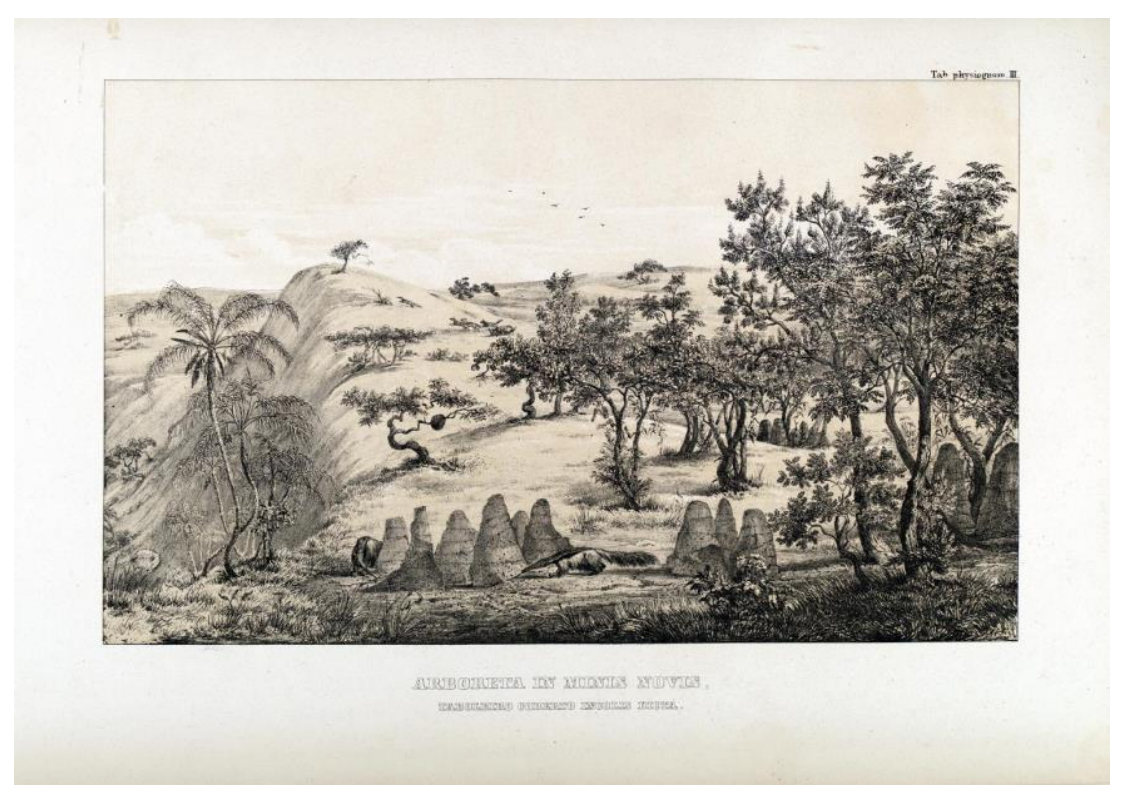

2.III. Os arvoredos de Minas Novas chamados pelo povo tabuleiro coberto, autoria atribuída a Martius, s/ data. Prancha de Flora Brasiliensis. Fonte: Flora Brasiliensis (1996)

Esta gravura é especialmente rica para o leitor de sua obra por mostrar vários elementos típicos da paisagem local. Nela se vê o que seriam os aspectos topográficos da região, mais aberto e menos montanhoso, animais nativos, como o tamanduá-bandeira no primeiro plano perto das casas de formigas (no original formiceta. Ou seriam casas de cupins?) e ao fundo, os lobos-guará que se encontram na elevação posterior às árvores, assim como variadas espécies arbóreas. Dentre elas, segundo a descrição de Martius, estão representadas a palmeira Cocus flexuosa no primeiro plano, a Erythroxylum suberosum, que está um pouco mais atrás e que serviria entre os nativos para tingir a lã de cor escura, a Aspidosperma macrocarpum, a Aristolochia gigantea, entre outras. O título da prancha também oferece o conhecimento de uma outra denominação para o cerrado, como o uso brasileiro observado

\footnotetext{
${ }^{12} \mathrm{http}: / /$ cidades.ibge.gov.br/painel/painel.php?lang=\&codmun=314180\&search=minas-gerais $/$ minasnovas/infograficos:-dados-gerais-do-municipio
} 
por Martius de "tabuleiro coberto". "São chamadas no país tabuleiro; quando os galhos das árvores se tocam, diz-se tabuleiro coberto, e havendo capoeira densa entre os caules tabuleiro cerrado" (MARTIUS, 1943, p. 257) ${ }^{13}$. Apesar de ser o clima dessa parte do cerrado geralmente bastante quente, a ilustração intenciona apresentar para o leitor uma paisagem calma e harmônica, em que diferentes espécies de animais e de vegetais sustentariam, cada qual com a sua função, a cadeia natural. Combinado com o traço suave com que estão desenhadas as plantas e com o equilíbrio de suas formas curvilíneas, o conjunto de pássaros ao fundo, no céu, completa a paisagem, a tornando um lugar tranquilo e agradável de se conhecer, onde "oferece-se aqui ao botânico a grata oportunidade de conhecer as flores de árvores que não poderiam ser encontradas em nenhum outro lugar" (MARTIUS, 1996, p. 29). Nesta prancha se observa uma clara tentativa de abarcar diversos elementos nativos em um cenário único e ideal. Mesmo que criada a paisagem a partir de uma "montagem" que incluía as espécies típicas da região, prática comum no contexto das viagens, a intenção era que o leitor pudesse ter, além do conhecimento, uma experiência geral dos ambientes percorrido. Algo que não desqualifica a imagem, mas, ao contrário, a qualifica por ser a percepção de uma época sobre o que se compreende enquanto natureza (SCHAMA, 1996; WILLIAMS, 2011).

Hercule Florence também descreve em Viagem fluvial do Tietê ao Amazonas de 1825 a 1829 a dinâmica da paisagem sobre a extensão do que atualmente se denomina Cerrado:

Atravessamos como nos dias anteriores vários cerrados, mas estes mudaram diversas vezes de viso. Aqui eram grandes árvores de folhagem escassa e cores várias, deixando ver um entrelaçamento de ramos retorcidos como o coral, de casca rugosa e enegrecidos pelo fogo; ali outras, cujas folhas haviam sido devoradas pelas chamas, ficando só a negra rama. Adiante tudo desabrochava em flores amarelas e roxas; mais longe não se via senão ramalhada seca, cujo matiz ia do pardo ao ruivo. Enfim nos terrenos úmidos reapareciam as flores amarelas, azuis, carmíneas e roxas. À tarde variou o panorama. Não era mais uma paisagem avivada alegremente por maciços floridos, mas um quadro grandioso. (FLORENCE, 2007, p.160)

Nessa passagem percebe-se como que a cada trecho percorrido pelo artista a paisagem se modificava e tomava outra feição. Não se pode esquecer que tanto Martius quanto Florence eram europeus que estavam acostumados com as florestas de suas terras

\footnotetext{
${ }^{13}$ Termo este também usado por Auguste Saint-Hilaire para se referir a um campo com árvores tortuosas. Em: QUINTELA, Antón Corbacho. Do sertão ao Cerrado do Planalto Central: uma questão de nomenclatura. Revista UFG, Ano XII, no 9, Dez. 2010.
} 
natais (hoje Alemanha e França, respectivamente), geralmente compostas por poucas espécies predominantes. A diversidade que compunha essa parte da mata brasileira parecia causar uma espécie de deslumbramento tanto por sua aparência quanto por suas qualidades naturais, ao ponto em que na parte da manhã, segundo as palavras de Florence, se tem uma paisagem bastante diferente da encontrada à tarde em uma caminhada realizada em um único dia. E essa variedade é relatada pelo artista quando ele escreve sobre as ramagens retorcidas, sobre as flores coloridas ou sobre o fogo que ali passou, chegando, ao fim, a alcançar alguma parte úmida do cerrado. "Pela grande variedade das paisagens, muito teria aqui um pintor em que exercitar o seu talento" (FLORENCE, 2007, p. 130). Florence, deste modo, percebe a diversidade paisagística que compõe essa parte do território brasileiro e, de fato, parece admirar essa pluralidade natural.

Por terreno chato e cheio de cerrados pouco vigorosos fizemos três léguas, vencendo, porém, depois duas e meia por outros dos mais luxuriantes em verdura, dos mais floridos que jamais víramos. Por todos os lados mostravam-se árvores cobertas de tal quantidade de flores que nenhuma folha aparecia. Assim umas eram totalmente amarelas, outras roxas, outras azuis, cor-de-rosa, carmíneas, o que produzia combinações gratas à vista.

O terreno tapizado de veludo verde era, ainda mais, esmaltado das mais lindas flores com o colorido vivo e ardente próprio da zona tórrida. Folhas, flores, gramado e plantas, tudo acabava de renascer com essa celeridade do clima que faz a gente crer que os vê crescerem e se expandirem. Ao calor do dia substituíra o frescor da tarde. Respiravam- se os mais sutis aromas; as mais esplêndidas cores brilhavam num fundo de céu ou de relva. 0 firmamento azulava e maciços de vaporosas nuvens transparentes e com cerúleos reflexos, sombras quase apagadas em roxas tintas, erguiam-se como Andes suspensos, cujos diversos planos davam perspectiva aos ares e ao olhar do espectador abriam as profundezas do espaço. (...) Um pintor que não tenha contemplado painéis feitos pela mão dos mestres poderia, parece-me, na composição de seus quadros, aprender com a natureza. (FLORENCE, 2007, p. 159) [grifo meu]

Neste trecho Florence está percorrendo as proximidades de Cuiabá, relatando os "cerrados" que compõe a vegetação da região. Vê-se que nesta passagem a escrita é dominada pelo encantamento do artista ante a beleza da flora, em que com as palavras ele "pinta" um quadro colorido e cheio de vida em seu relato.

Já no seguinte desenho Florence (Fig.3) mostra bem como deveria ser uma paisagem do cerrado na época, tendo um aspecto semelhante à atualidade. 


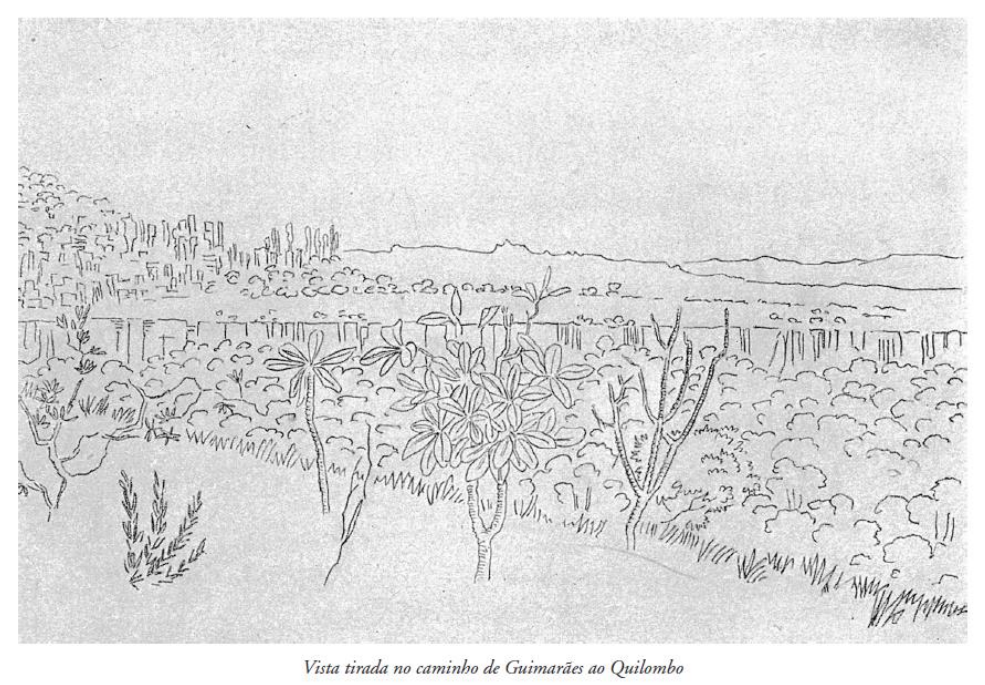

3. Vista tirada no caminho de Guimarães ao Quilombo. Florence, s/ data. Fonte: Florence (2007)

Nessa paisagem se vê plantas baixas, predominando arbustos, plantas mais altas espaçadas, gramíneas no primeiro plano, troncos secos e retorcidos e uma formação rochosa que se assemelha a uma chapada, com montes ao fundo. Pode-se ver que, em concordância com o relato de Martius, Florence ilustra os arbustos predominantes no segundo plano como uma vegetação bastante densa e emaranhada, aproximando-se das formações campestres. Percebe-se nessa imagem um ambiente mais árido devido às características da vegetação e pelos espaços vazios que o artista manteve, o que dá um aspecto de maior isolamento. Outro fator que contribui para a impressão de aridez é a ausência de folhas e flores na planta que ocupa o centro mais ao canto direito do primeiro plano, restando dela somente o seu tronco e os seus galhos secos. Esta parece ser uma paisagem inóspita, ausente de grandes ocupações humanas, assim como relatado pelo artista sobre os arredores do que seria atualmente a região da Chapada dos Guimarães, no Mato Grosso, onde era presente a miséria dos indígenas e a decadência das vilas e “aldeolas" (FLORENCE, 2007, p. 145) ${ }^{14}$.

A imagem 4 é ocupada em grande parte pela ilustração de uma composição rochosa formada por filamentos de arenito (vermelho), típica e marcante ainda hoje nas proximidades de Cuiabá. Os traços horizontais que Florence usa para representar as rochas em meio às vegetações mostra de maneira fidedigna a singular paisagem de arenito.

\footnotetext{
${ }^{14}$ Florence em seu relato disserta brevemente sobre a presença da mineração nessas terras (FLORENCE, 2007).
} 

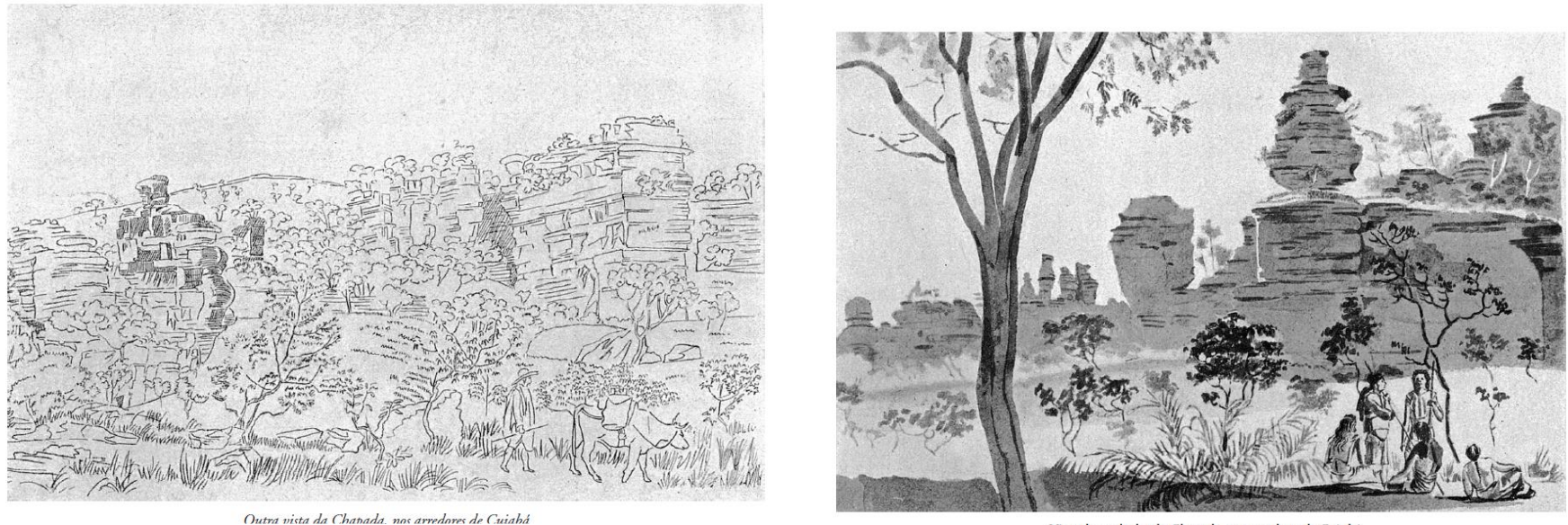

Vista dos rochedos da Chabada. nos arredores de Cuiabá

4.Outra vista da Chapada, nos arredores de Cuiabá, Florence. Fonte: Florence (2007)

5. Vista dos rochedos da Chapada, nos arredores de Cuiabá, Florence. Fonte: Florence (2007)

Nesta mesma ilustração visualizam-se, igualmente à imagem anteriormente analisada, gramíneas, árvores baixas e arbustos predominando por toda a composição, apresentando uma paisagem de aspecto seco e sem muitas variações. As paisagens de Florence costumam de fato ser bastante objetivas, ficando claro que o seu interesse é demonstrar de modo fidedigno as características de cada região percorrida. Com isso as suas imagens em geral parecem ter poucas adições que tenham a finalidade de criar um cenário mais fantasioso. Assim, com o mesmo traçado usado para compor a vegetação, o artista faz no primeiro plano um homem com trajes típicos guiando um boi que parece de carga: "Em viagem, é de uso servirem os bois mansos de animal de carga" (FLORENCE, 2007, p. 126), sugerindo a presença do gado nas proximidades. Na descrição sobre a cidade de Cuiabá Florence diz que "Cria-se muito gado vacum que por toda a parte encontra excelentes pastos" (idem). No entanto, ele comenta que nessa região a agricultura e a criação de animais era feita somente para suprir as "necessidades da alimentação". Na época em que Florence passou por essas terras, em 1827, a decadência da mineração ainda era bastante visível e um desenvolvimento agropastoril ainda estaria por vir. Mas é interessante notar que no material que o artista nos deixou é feita a observação sobre o animal e sobre a característica da extensão de terras que, segundo a sua opinião, eram adequadas para a pastagem. Sobre uma maior criação de gado no Mato Grosso o viajante comenta sobre a 
famosa Fazenda Jacobina, "a mais rica fazenda da província" ${ }^{15}$, do coronel de milícias João Pereira Leite: "Gado imenso cobria as ricas pastagens da Jacobina e outras fazendas [do mesmo coronel]. O dono avaliava seu número em 60.000 reses; a maior parte, porém, tornara-se selvática" (FLORENCE, 2007, p, 165). Segundo o autor, o que era produzido na fazenda era exportado pela própria província, não entrando em maiores detalhes sobre a pecuária. E Eis que atualmente o Mato Grosso se reconhece como o "celeiro do país" 16 pela grande produção de grãos e de rebanho bovino, que ao lugar de uma antiga produção de subsistência hoje atende ao um mercado internacional impiedoso.

Mas o que parece realmente deslumbrar Florence é a paisagem da Chapada dos Guimarães, a qual não foi por ele simplesmente avistada, mas foi profundamente sentida: "mas se a natureza tudo me negou, por que me concedeu o dom de sentir com tanta força?" (FLORENCE, 2007, p.130). Ele faz comentários sobre os seus rochedos - os quais também podem ser vistos na imagem 5 - num tom em que, diferentemente das suas imagens, poesia e realidade parecem se encontrar ao avistar formações tão singulares e "majestosas":

Atravessa-se, então, uma planície cheia de contrafortes circulares encostados aos montes, como se houvessem sido primeiro construídos para, com aterro de rochas e terra, sustentarem esplanadas artificiais, onde árvores e relva produzem a impressão de jardins suspensos. Do meio desses contrafortes saem umas espécies de enormes pedestais, circulares e emoldurados, alguns até com restos de colunas. $O$ caminho plano serpenteia por entre essas majestosas massas que para nós se destacavam num céu toucado das suaves cores do crepúsculo.

Nos montes e na planície, por toda parte, avistam-se grupos de pedras que, com os contrafortes, semelham os restos de uma cidade imensa, em que durante séculos imperara a mais nobre arquitetura. Fica a gente pasma ao achar-se de repente no meio de uma natureza que fala linguagem desconhecida até então, pois onde só há rochas julga-se ver os destroços de soberbos monumentos levantados por uma raça de arquitetos gigantes. (FLORENCE, 2007, p. 138)

Além das informações detalhadas e cheias de entusiasmo como essa passagem, as paisagens registradas por Florence através de palavras e imagens sugerem também possíveis interferências humanas no passado. Uma planta citada por ele que me chamou a atenção durante a leitura de seu relato de viagem foi a Embaúba (gênero Cecropia). Tal árvore, composta de várias espécies, pode atuar como indicador de formações instáveis

\footnotetext{
${ }^{15}$ Segundo o IBGE: " A Fazenda Jacobina destacava-se na primeira metade do século XIX por ser a maior da província de Mato Grosso em termos de área e produção." Ver mais em: http://biblioteca.ibge.gov.br/biblioteca-catalogo.html?view=detalhes\&id=31358

${ }^{16} \mathrm{http}: / /$ www.mt.gov.br/economia
} 
(beiras de rios, por ex.) ou de distúrbios pretéritos, sejam eles de ordem natural ou antropogênicos, tais como áreas de queimadas, naturais ou não, pastos, áreas agrícolas ou antigas roças abandonadas. A abertura de clareiras e, portanto, a disponibilidade de luz é um importante fator para a sua ocorrência, por isso é ausente um maior número de embaúbas em florestas antigas (devido ao sombreamento que pode ocorrer por espécies maiores). Por ser encontrada também em áreas degradadas e por poder ser ela uma planta pioneira, o relato de Florence deixa a questão se ele estaria passando por uma parte de mata regenerada ou se simplesmente estaria se deparando com uma espécie comum na região. Assim ele diz: “Desenhei uma embaúba, notável pelo tamanho, espessa folhagem verde desmaiada, e ramos tortuosos embora horizontais" (FLORENCE, 2007, p. 161). Essa passagem foi escrita no dia 29 de agosto, quando a caminho de Vila Maria, hoje Cáceres ${ }^{17}$, em Mato Grosso. Fica a dúvida de como essa espécie foi surgir por essas terras por falta de maiores informações, no entanto de acordo com o seu relato a exploração aurífera era ainda feita na região, prática ambientalmente bastante degradante devido às erosões provocadas e à contaminação do solo por mercúrio, entre outros males: “É o destino dos países onde os homens só se ocupam na exploração das minas: nada se funda durável. O solo pedregoso desse lugar dá ainda ouro de qualidade superior, mas essa gente, não sabendo senão esgaravatar a terra, só conseguia pequenas quantidades do metal" (FLORENCE, 2007, 160). Será que essa embaúba representaria um distúrbio pretérito ocasionado por esse tipo de exploração? Difícil saber, mas sua presença poderia indicar a possibilidade de um uso pretérito do solo ${ }^{18}$.

Outra curiosidade é quando nas proximidades da embocadura do Rio Pardo (localizado na divisa dos atuais estados de São Paulo e Mato grosso do Sul), Florence comenta sobre a presença de laranjeiras naquela região ainda pouco habitada: "Dia 18. Vimos umas laranjeiras que mão benfazeja ou o acaso havia feito nascer naqueles desertos. Colhemos

\footnotetext{
${ }^{17} \mathrm{http} / / /$ biblioteca.ibge.gov.br/biblioteca-catalogo.html?view=detalhes\&id=31358

${ }^{18}$ Professor de geografia e historiador ambiental Rogério Oliveira tem feito diversos estudos e análises que integram documentos teóricos e evidências paisagísticas. Trabalhando com os paleoterritórios ele e seus colegas têm chegado a conclusões sobre ocupações pretéritas em regiões "ausentes de história", devido ao fato de não haver documentos escritos sobre determinadas localidades que são atualmente florestas e que outrora, de alguma forma, tiveram a presença humana. A partir, então, de evidências encontradas na composição da terra, em espécies e na formação da flora, em vestígios de antigas construções, entre outros, o historiador e sua equipe tem usado conjuntamente também os relatos de viajantes para resgatar informações relacionadas às florestas da Mata Atlântica. Ver: Rogério Oliveira, Fruto da terra e do trabalho humano: paleoterritórios e diversidade da Mata Atlântica no Sudeste brasileiro Revista de História Regional 20, 2 (2015): 277-299.
} 
alguns frutos ainda verdes, que, contudo, muito apreciamos." (FLORENCE, 2007, p. 58). É interessante notar que uma espécie exótica, provável resquício de uma antiga roça ou pomar, habitava aqueles "desertos"19, mostrando que essas terras de aparência tão errante tinham em alguns trechos indícios de paisagens antrópicas. O próprio Florence parece estranhar a presença da fruta naquele cenário ao atribui-la ao acaso, como se de fato não houvesse uma explicação plausível no momento para essa aparição tão inusitada. Nessa mesma região do Rio Pardo Florence cita também alguns frutos silvestres, descrevendo os agradáveis sabores do marmelo-brabo, da mangaba e do caju.

Um outro indício de desmatamento é o seu testemunho sobre a prática da coivara para a pastagem nas cercanias de Cuiabá por parte dos habitantes locais:

De pronto não nos era fácil adivinhar a razão por que todos os troncos e ramos das tortuosas árvores desses cerrados negrejavam como azeviche e o capim resplendia de verde tão uniforme. É que o fogo por ali passara e que tudo ressurgia simultaneamente; devendo esse hábito do caipira, que sem trabalho quer todos os anos renovar as pastagens para seu gado, produzir a esterilidade dessas belas regiões, caso não repare cultura mais inteligente tantos e tão seguidos estragos. (FLORENCE, 2007, p.160)

Nota-se que Florence vê tal hábito como uma coisa negativa por esterilizar a terra dessas "belas regiões". Na verdade, o debate sobre o "adequado" uso do solo já era algo presente na Europa e também no Brasil desde o século XVIII, já havendo uma comunicação internacional entre os críticos ambientais que se seguiu pelo século XIX. "Essa comunicação expressava-se através de uma rede de academias científicas e jardins botânicos, que foram sendo criados por toda parte" (PÁDUA, 2004, p. 55). Por outro lado, na imagem (Fig.6) e na passagem que segue Florence dá um sabor espetacular e quase sublime à cena devastadora de um incêndio nas imediações do Rio Pardo:

Quando a gente por desenfado atira fogo aos campos que cercam os acampamentos, o espetáculo à tarde se transforma, mas nem por isso é menos notável. As labaredas se alargam, formam linhas de compridas chamas que sobre todos os objetos deitam claridade resplandecente, por tal modo intensa que se pode enxergar um alfinete caído no chão. Essa linha de fogo se afasta, estende-se em grandes círculos, sobe e transmuta por vezes outeiros. Clarões vivos se desprendem, destacando-se de sombras opacas. Rolos de fumo enevoam os céus: o rio parece fogo e as

\footnotetext{
${ }^{19}$ A palavra deserto era usada pelos viajantes, muitas vezes, no sentido de ermo, lugar inabitado, não ocupado pelo o que entendiam como civilização. Nessa passagem, parece que foi assim utilizada, pois ele estava descendo o rio Paraná e fazendo acampamentos nas proximidades de suas margens, provavelmente na época compostas de vegetações mais viçosas.
} 
taquaras nos bosques estouram, dando violenta saída ao ar contido entre os nós e que se dilata com o calor repentino.

Não raramente gozávamos daquela esplêndida iluminação até depois de meia-noite. (FLORENCE, 2007, p. 59)

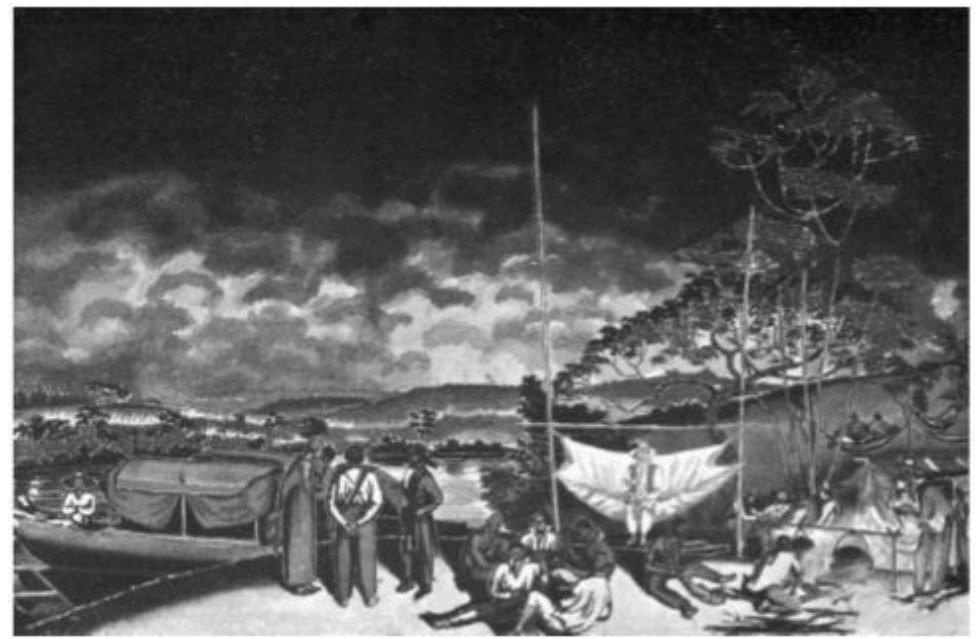

6.Rio Pardo. Queimada nos campos, Florence, s/ data. Cena de queimada presenciada pelos viajantes em acampamento. Fonte: Florence (2007)

Martius também comenta sobre a prática das queimadas para a renovação do solo em Flora Brasiliensis, fazendo igualmente o registro visual (Fig.7) dessa ocorrência.

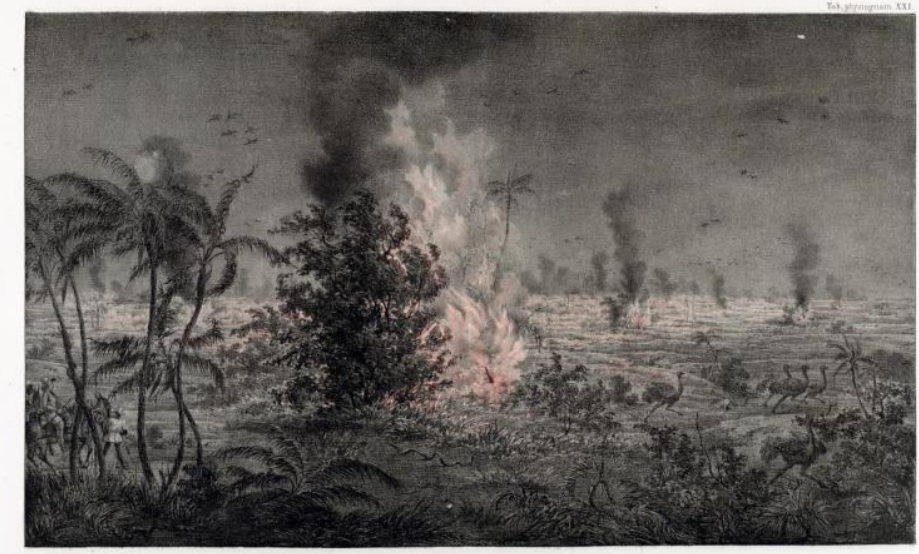

7.Prancha XXI. Espetáculo noturno de um campo queimado por fogos no verão seco, na região ocidental da província de Minas. Autoria atribuída a Martius. Fonte: Flora Brasiliensis (1996)

Esta estampa ilustraria a constância dos incêndios na região de Minas no período da seca, em que, segundo o autor, capim e ervas eram queimados "pelo ardor do sol tropical" (ardore solis tropici comburuntur), virando palha. Martius também comenta que os brasileiros achavam positiva a destruição dessas plantas secas ateando fogo no terreno com o intuito de preparar o solo para o cultivo de grãos e para as pastagens (MARTIUS, 1996). No texto que acompanha a prancha Martius observa a intenção dos agricultores brasileiros de limpar o solo 
das ervas "nocivas", como é o caso da chamada "barba de bode" (ele poderia estar se referindo à Cyperus compressus), dizendo que os habitantes locais julgavam ser correto banir essas estípulas e palhas através do fogo que se propagava bem em terreno árido e com o vento certo, sendo que as cinzas também iriam contribuir para a fertilidade do solo. É interessante notar que quando Martius diz que "o agricultor brasileiro, cujo método na colheita regular o afasta, de resto, do conhecimento e da técnica correta da cultura dos prados (...)" (MARTIUS, 1996, p.85) ele faz uma crítica às queimadas como incorretas; o que fica mais claro em palavras ditas em outras partes de Flora Brasiliensis. E assim ele termina o comentário sobre esse "espetáculo" incendiário, o comparando com a trágica passagem bíblica referente à perseguição ao povo judeu por parte dos soldados israelitas:

Uma única coisa acrescentamos: que, caminhando por estes desertos que se inflamam, vemos, frequentemente, nuvens, por vezes negras, cintilando do cimo, à noite, nuvens que os ventos reúnem da cinza e da fumaça e avançam pelos campos, horríveis de ver; o mesmo espetáculo que as colunas de nuvens ofereceram aos israelitas que marchavam pelo deserto (Exodus $\mathrm{c}$. XIII. V. 21) (MARTIUS, 1996, p. 85)

Mas há que ter em mente que as críticas feitas tanto por Florence quanto por Martius se dirigiam à deterioração de uma terra que poderia ser melhor aproveitada se manuseada adequadamente, uma vez que o progresso de uma civilização dependia também do bom aproveitamento dos seus recursos naturais.

Assim, em suas longas caminhadas pelos "cerrados" ambos viajantes avistavam o que havia de mais curioso ou de mais singelo, mas também o que havia de mais aterrador, ou até poético.

\section{Conclusão}

Essas imagens foram capazes, assim, de trazer aspectos das paisagens do Cerrado que podem ser analisados para efeitos de visualização e auxílio para o conhecimento sobre a transformação da paisagem de uma dada região. Também através da iconografia podem ser visualizados os usos pretéritos da terra de um determinado lugar, como a prática da coivara e a pecuária, por exemplo, ainda recorrente em grande parte do Brasil central. Entretanto, é fundamental fazer o uso das imagens sempre atento à percepção dos seus autores e em que contexto foram realizadas (como qualquer outra fonte). Da mesma forma é importante considerar aspectos da imaginação e interpretação do artista, uma vez que vindo de outra cultura ele vai representar as paisagens a sua maneira. Algo que na minha 
opinião é bastante positivo porque tais obras são resultantes da experiência do sujeito com o ambiente, e da adequação deste, até então desconhecido, aos padrões artísticos europeus (NAXARA, 2004). Entretanto, por serem essas gravuras, desenhos e pinturas resultados das vivências dos lugares esses mesmos padrões tiveram também que se flexibilizar e se adequar às novas formas, às novas luzes e cores inéditas que o cerrado apresentava. E se se compreende, pelo viés da história ambiental, que o que chamamos natureza é a interação entre ser humano e meio biofísico, tais imagens são autênticos testemunhos dessa influência mútua, pois contém junto às informações sobre as ciências naturais a cultura e a experiência do seu observador.

Assim, as "savanas" brasileiras, que à primeira vista Ihes pareceram como agrestes e monótonas por sua aparência arbustiva e seca predominante, apresentou a eles surpresas por sua singularidade e ineditismo. Seu aspecto peculiar de regeneração se mostrou deslumbrante e único, ficando visível para esses estrangeiros a diversidade de riquezas que eram existentes nesses conjuntos vegetacionais. $\mathrm{O}$ que quis expor neste artigo foi justamente esse olhar para a diversidade dessas matas, que provocaram sensações de exaustão em alguns momentos, devido às imensas extensões de mata "cerrada", mas que foram em parte superadas pela percepção atenta sobre as suas características mais peculiares, onde a beleza da Flora surgia dentre os galhos mais "tortuosos". Deste modo, as imagens e os relatos de Florence e de Martius não se detiveram somente à impressão de estranhamento desses "campos", mas avançaram também para a beleza e para a força de sua peculiaridade: "Também o encanto da novidade exaltou ainda mais o bem-estar, que em nós infundia uma natureza inimiga da monotonia e pródiga, sobretudo para o viajante, de novas perspectivas" (FLORENCE, 2007, p. 160).

\section{REFERÊNCIAS BIBLIOGRÁFICAS}

BERTRAN, Paulo. História da terra e do homem no Planalto Central: eco-história do Distrito Federal. Brasília: Editora da Universidade de Brasília, 3a. edição, 2011.

COUTINHO, Leopoldo Magno. O conceito de bioma. Acta Bot. Bras., São Paulo, v. 20, n. 1, p. 1323, Mar. 2006 . Available from <http://www.scielo.br/scielo.php?script=sci_arttext\&pid=S010233062006000100002\&Ing=en\&nrm=iso>. access on 19 Sept. 2017.

DELLA GIUSTINA, Carlos Christian. Degradação e conservação do cerrado: uma história ambiental do estado de Goiás. 2013. 210 f., il. Tese (Doutorado em Desenvolvimento Sustentável) - Universidade de Brasília, Brasília, 2013. 
DUTRA E SILVA, Sandro; PIETRAFESA, José Paulo; FRANCO, José Luiz Andrade; DRUMMOND, José Augusto; TAVARES, Giovana Galvão (orgs). Fronteira Cerrado: Sociedade e Natureza no Oeste do Brasil. Goiânia: Ed. PUC de Goiás, 2013.

DUTRA E SILVA, SANDRO; MOURA, T. T. R. L. ; CAMPOS, Francisco Itami . A fronteira do gado e a história do oeste brasileiro: coronelismo, violência e dominação fundiária em Goiás. In: História Ambiental (vol. 2). Franco (org.) Rio de Janeiro: Garamond, 2016.

FLORENCE, Hercules. Viagem Fluvial do Tietê ao Amazonas de 1825 a 1829. Brasília: Senado federal, Conselho Editorial, 2007.

FUNES, Eurípedes. Sertão Cerrado. In: Fronteira Cerrado: Sociedade e Natureza no Oeste do Brasil. Dutra e Silva (org.) Goiânia: Ed. Puc Goiás, 2013.

MARTIUS, C. F. von (1840) A viagem de von Martius - Flora Brasiliensis. Rio de Janeiro: Index., 1996. . A Fisionomia do reino vegetal no Brasil (1824). Curitiba: Arquivos do Museu Paranaense, 1943.

NAXARA, Marcia Regina Capelari. Cientificismo e sensibilidade romântica. Brasília: Editora UNB, 2004.

PÁDUA, José Augusto. Um sopro de destruição: pensamento político e crítica ambiental no Brasil escravista, 1786-1888 - 2.ed. - Rio de Janeiro: Jorge Zahar Ed., 2004

. Um País e Seis Biomas - Ferramenta Conceitual para o Desenvolvimento Sustentável e a Educação Ambiental. In: Pádua, J.A., (Org.) Desenvolvimento, Justiça e Meio Ambiente. Belo Horizonte: Universidade Federal de Minas Gerais, 2009.

RIBEIRO, Ricardo. O Eldorado do Brasil central: história ambiental e convivência sustentável com o Cerrado. In: Ecología Política. Naturaleza, sociedad y utopia. Buenos Aires: CLACSO, abril de 2002.

RIBEIRO, J.F. \& WALTER, B.M.T. As principais fitofisionomias do bioma Cerrado. In: SANO. S.M., S.P. ALMEIDA, \& J.F. RIBEIRO (eds.). Cerrado: ecologia e flora. Embrapa Cerrados. Brasília-DF, p. 153-212, 2008.

RICOTTA, Lúcia. A paisagem em Alexander von Humboldt: o modo descritivo dos quadros da natureza. Revista USP, São Paulo, n. 46, p. 97-114, jun./ago. 2000.

SHAMA, S. Paisagem e Memória. São Paulo: Companhia das Letras, 1996.

SPIX e VON MARTIUS. Viagem pelo Brasil (1817-1820). São Paulo: Edusp, 3 vols., 1981.

WALTER, Bruno Machado Teles. Fitofisionomias do bioma Cerrado: síntese terminológica e relações florísticas. 2006. 389 f., il. Tese (Doutorado em Ecologia) -Universidade de Brasília, Brasília, 2006.

WILLIAMS, R. Ideias sobre a Natureza. In: Cultura e Materialismo. São Paulo: Ed. Unesp, 2011. 